\title{
Sulfur nutrition of oil palm for enhancing oil yield in tropics
}

\begin{abstract}
Globally, the demand for vegetable oil is increasing due to tremendous growth in the world population. Among vegetable oils, palm oil contributes a major share $(33 \%)$ in annual consumption of vegetable oil around the world. The yield of palm oil has witnessed an unprecedented increase in the last few decades, mainly due to the increase in area under oil palm plantation. However, the prospects for increasing palm oil yield due to the increase in area under oil palm cultivation are very bleak as possible areas have already been brought under oil palm plantation. Moreover, palm oil yield per unit area has been stagnant over the last decade. Mainly, oil palm is grown in Oxisols and Ultisols which are highly weathered soils having inherently low fertility status. Soil fertility management is therefore prerequisite to realizing the maximum yield potential of oil palm in such low fertility soils. Sulfur is an essential macronutrient that has a very crucial role in oil biosynthesis in oil seed crops. Sulfur is generally deficient in Oxisols and Ultisols and thus needs proper consideration for enhancing the oil yield of oil palm. But sulfur is least considered in soil fertility and nutrient management programs of oil palm plantations. We have reviewed the literature to highlight the role of sulfur in the biosynthesis of oil in oil seed crops in general and oil palm in particular and have suggested some suitable measures for sulfur management of oil palm plantations for enhancing oil yield in highly weathered soils of Oxisols and Ultisols.
\end{abstract}

Keyword: Oil biosynthesis; Oxisols and ultisols; Palm oil; Sulfur; Vegetable oil 